Provided for non-commercial research and education use. Not for reproduction, distribution or commercial use.

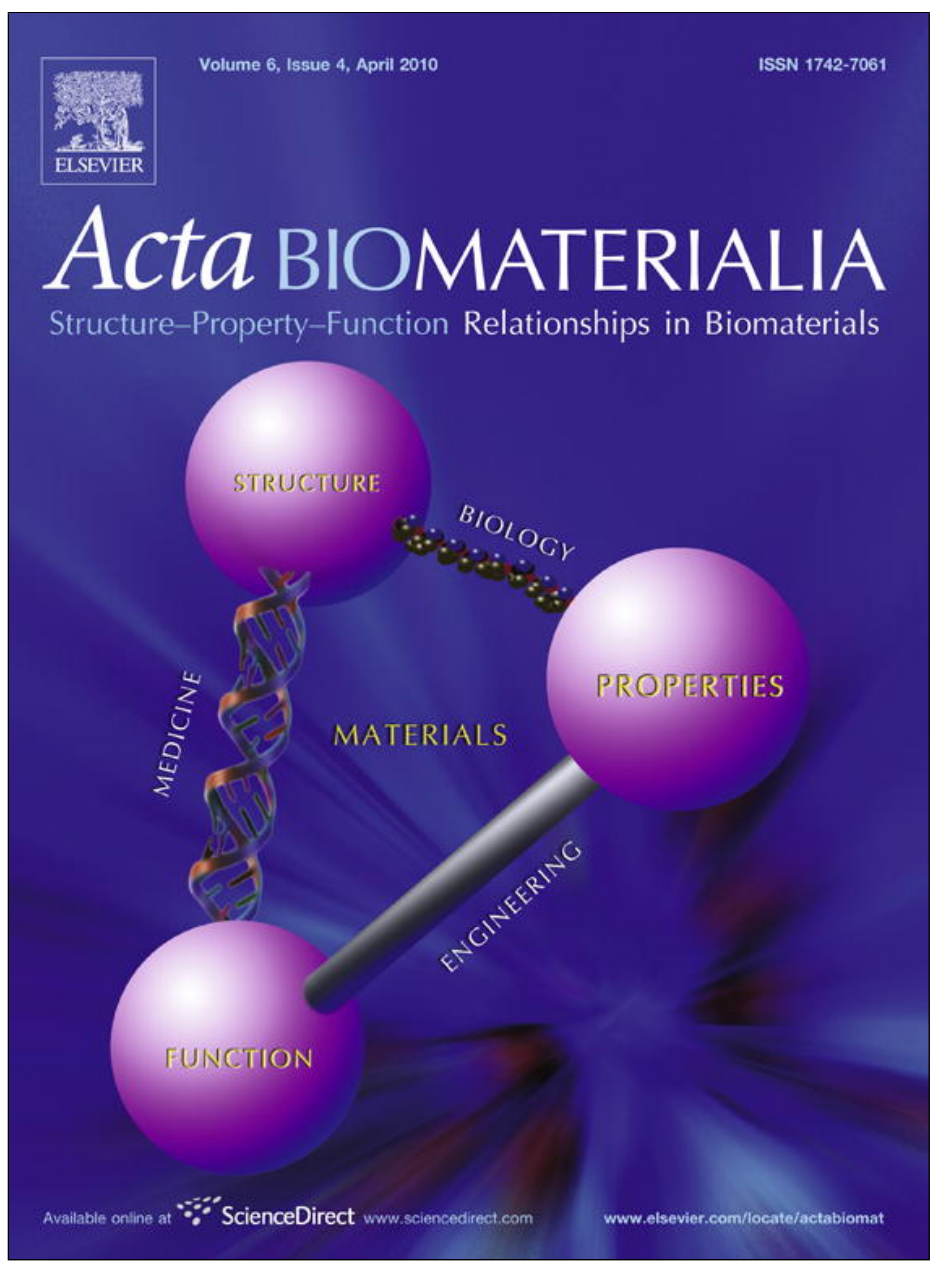

This article appeared in a journal published by Elsevier. The attached copy is furnished to the author for internal non-commercial research and education use, including for instruction at the authors institution and sharing with colleagues.

Other uses, including reproduction and distribution, or selling or licensing copies, or posting to personal, institutional or third party websites are prohibited.

In most cases authors are permitted to post their version of the article (e.g. in Word or Tex form) to their personal website or institutional repository. Authors requiring further information regarding Elsevier's archiving and manuscript policies are encouraged to visit:

http://www.elsevier.com/copyright 
Brief communication

\title{
Cobalt, chromium and nickel affect hydroxyapatite crystal growth in vitro
}

\author{
G. Mabilleau ${ }^{\mathrm{a}, *}$, R. Filmon ${ }^{\mathrm{b}}$, P.K. Petrov ${ }^{\mathrm{c}}$, M.F. Baslé ${ }^{\mathrm{b}}$, A. Sabokbar ${ }^{\mathrm{a}}$, D. Chappard ${ }^{\mathrm{b}}$ \\ ${ }^{a}$ Nuffield Department of Orthopaedics, Rheumatology and Musculoskeletal Sciences, University of Oxford, Oxford, UK \\ ${ }^{\mathrm{b}}$ INSERM, U922, LHEA, Faculty of Medicine, University of Angers, Angers, France \\ ${ }^{\mathrm{c}}$ Department of Materials, Imperial College London, London, UK
}

\section{A R T I C L E I N F O}

\section{Article history:}

Received 7 July 2009

Received in revised form 20 October 2009

Accepted 21 October 2009

Available online 25 October 2009

\section{Keywords:}

Metal

Mineralization

Hydroxyapatite

Crystal size

Crystallinity

\begin{abstract}
A B S T R A C T
Metals are widely used in orthopaedics and recent studies have reported that patients with metal implants have a significant increase of metal levels in serum and synovial fluid. Femoral neck fracture occurred in some patients with metal-on-metal implants for unknown reasons. Recently, bone quality has emerged as an important factor of bone strength and few studies have investigated the effects of metal ions on hydroxyapatite properties. In the present study, we investigated the effects of $\mathrm{Co}^{2+}, \mathrm{Cr}^{3+}$ and $\mathrm{Ni}^{2+}$ on hydroxyapatite (HA) growth in vitro, using carboxymethylated poly(2-hydroxyethyl methacrylate) (pHEMA) as a biomaterial for calcification. We have demonstrated that metal ions reduced the quantity of mineral formed at the surface of the polymer and decreased the ratio Ca/P by 1.12-, 1.05and 1.08-fold for $\mathrm{Cr}^{2+}, \mathrm{Cr}^{3+}$ and $\mathrm{Ni}^{2+}$ respectively. Furthermore, the size of calcospherites was significantly increased in the metal-doped HA compared to the controls, indicating a possible effect of metal ions on the crystal lattice. Indeed, the presence of metal ions increased the crystal size as well as the crystallinity of HA and reduce the lattice parameter $c$ of the HA framework. The information obtained from this work suggests that the quality of the mineral around metallic implants could be altered. However, further investigation should be conducted to further elucidate the effects of metal incorporation on bone mineral and the functional consequences.
\end{abstract}

(c) 2009 Acta Materialia Inc. Published by Elsevier Ltd. All rights reserved.

\section{Introduction}

Metals are essential for the survival of animals, plants and microorganisms [1]. Because of their different state of oxidation, some of them are a useful component of enzymes and metalloproteins [2]. In healthy volunteers, metal levels are very low and are considered as trace elements. However, metal levels are considerably raised in patients with metal prostheses independently of the bearing couple [3], and the consequence of such concentrations on the body is relatively unknown. Recent studies have reported that patients undergoing metal-on-metal (MoM) resurfacing have elevated serum levels of $\mathrm{Co}\left(1.0 \mu \mathrm{g} \mathrm{l}^{-1}\right)$ and $\mathrm{Cr}$ ions $\left(0.8 \mu \mathrm{g} \mathrm{l}^{-1}\right)$ [4,5], as well as increased levels in synovial fluids $\left(0.3 \mathrm{mg} \mathrm{l}^{-1}\right.$ of $\mathrm{Co}$ and $1 \mathrm{mg} \mathrm{l}^{-1}$ of Cr) $[6,7]$. Some of these patients also developed neck narrowing and, in a recent cohort of 377 patients, Little et al. [8] reported that $4 \%$ of the patients had undergone femoral neck fracture. Although there is a growing body of evidence that the bone mineral density (BMD) is decreased around the implant in the first postoperative months, this could be attributed to the operation itself, as BMD seemed to increase after 3 months post-surgery [9-11]. Recent reports suggest that, besides bone density, other factors, often referred

\footnotetext{
* Corresponding author. Tel.: +44 1865227964.

E-mail address: guillaume.mabilleau@ndorms.ox.ac.uk (G. Mabilleau).
}

as "bone quality", influence bone strength. Nowadays, it is widely accepted that bone strength depends on both bone quantity and quality, a term encompassing structural and material properties. Inside the cells, metals undergo oxido-reduction reactions which lead to the generation of free radicals (reactive oxygen species and reactive nitrogen species) (see the review in Ref. [12]). Fleury et al. [13] reported that metal ions induce osteoblast death mainly by increasing the levels of oxidated and nitrated proteins. These free radicals can also attack the DNA double strand and induce damage to purine and pyrimidine bases, as well as to the deoxyribose backbone. Free radicals can also induce crosslinks in DNA and they catalyse the oxidation of phospholipids (a process known as lipid peroxidation) [1416]. Furthermore, Nichols and Puleo [17] showed that in bone marrow cultures exposed continuously to cobalt and chromium ions there was a significant decrease in the total area resorption. On the other hand, Rousselle et al. [18] documented that exposure of mature rabbit osteoclasts to cobalt ions increased the number of osteoclasts. Metal overload can damage not only the cellular compartment of the bone matrix but also the organic phase [19,20]. Recent studies have reported that strontium, aluminium and iron can be incorporated in the mineral during the mineralization process and could affect its crystal properties [19,21-23]. However, it is still unknown whether cobalt, chromium and nickel ions can affect the mineral properties during physiological crystal growth. 
The aim of the present study was to investigate the role of cobalt, chromium and nickel ions on the in vitro growth of hydroxyapatite crystals, which represents the mineral component of bones. We employed a polymer poly(2-hydroxyethyl methymethacrylate), modified by carboxymethylation (pHEMA-CM), which can mimic the calcification of woven bone in the absence of cells $[19,24,25]$. Polymer disks were incubated in a synthetic body fluid containing metals at a concentration found in the vicinity of the implant [6]. The hydroxyapatite growth in the presence of metal ions was assessed by chemical analysis, scanning electron microscopy and X-ray diffraction. We found that cobalt, chromium and nickel ions can be incorporated into the mineral during crystal growth and that they dramatically affected the crystal size and crystallinity of hydroxyapatite.

\section{Material and methods}

Commercial 2-hydroxyethyl methacrylate (HEMA) was purchased from Sigma-Aldrich Chemical (Illkirsh, France). Commercial HEMA contains residual methacrylic acid and crosslinkers due to the fabrication process. The polymerization inhibitor 4Ùmethoxyphenol (added by the manufacturer before shipping, at a concentration of $350 \mathrm{ppm}$ ) also needs to be removed. HEMA was purified and distilled under reduced pressure $\left(5 \times 10^{-2} \mathrm{mBar}\right.$, $\left.65^{\circ} \mathrm{C}\right)$. Others chemicals were used as received.

\subsection{Assessment of osteoclast formation and activation}

The linear polymer was prepared by bulk polymerization. Briefly, the polymerization mixture was composed of HEMA $(10 \mathrm{ml})$ and $0.2 \mathrm{~g}$ of benzoyl peroxide was used as the initiator. The mixture was accelerated by $\mathrm{N}, \mathrm{N}$-dimethyl-para-toluidine. The ratio of benzoyl peroxide to $\mathrm{N}, \mathrm{N}$-dimethyl-para-toluidine was 100:1 (mol:mol). Monomers were polymerized at $4{ }^{\circ} \mathrm{C}$ for $2 \mathrm{~h}$ in polypropylene wells (Delta Microscopies, Labege, France). In that way, calibrated disks of pHEMA $(150 \pm 5 \mathrm{mg})$ were regularly obtained. Carboxymethylation of the disks was done as reported previously [24].

\subsection{Incubation of pellets in synthetic body fluid}

A standard synthetic body fluid (SBF) mimicking lymph fluid was prepared according to Yamada et al. [26]. Its composition was as follows: $\mathrm{Na}, 142.19 \mathrm{mmol} \mathrm{l}^{-1}$; $\mathrm{Ca}, 2.49 \mathrm{mmol} \mathrm{l}^{-1}$; $\mathrm{Mg}$, $1.5 \mathrm{mmol} \mathrm{l}^{-1} ; \mathrm{HCO}_{3}, 4.2 \mathrm{mmol} \mathrm{l}^{-1} ; \mathrm{Cl}, 141.54 \mathrm{mmol} \mathrm{l}^{-1} ; \mathrm{HPO}_{4}$, $0.9 \mathrm{mmol} \mathrm{l}^{-1} ; \mathrm{SO}_{4}, 0.5 \mathrm{mmol}^{-1}$; and $\mathrm{K}, 4.85 \mathrm{mmol} \mathrm{l}^{-1}$. Disks of carboxymethylated pHEMA (pHEMA-CM) were sterilized by ultraviolet radiation ( $360 \mathrm{~nm}$ for $3 \mathrm{~h}$ ) and were distributed in sterile-capped Falcon tubes containing $50 \mathrm{ml}$ of SBF during 21 days at $37^{\circ} \mathrm{C}$ to allow formation of calcospherites at the surface. The SBF was replaced every other day. To investigate the effects of metal ions on the mineralization process, the SBF was enriched with $100 \mu \mathrm{mol} \mathrm{l}^{-1}$ of $\mathrm{Co}^{2+}, \mathrm{Cr}^{3+}$ or $\mathrm{Ni}^{2+}$. At the end of the incubation period, the disks were rinsed in deionized water three times for $10 \mathrm{~min}$ to remove any noncrystallized ions. Thirty-six disks were incubated and randomly allocated into four groups. Among the nine disks per group, three underwent chemical analysis, three were prepared for scanning electron microscopy and three were used for X-ray diffraction.

\subsection{Chemical analysis}

Transfer of the disks into $1 \mathrm{ml}$ of $0.2 \mathrm{M} \mathrm{HCl}$ for $24 \mathrm{~h}$ led to the complete dissolution of calcospherites. The fluid was then collected and used to determine the amount of free ions on an auto- mated Hitachi 917 spectrophotometer (Roche, France) with standardized clinical reagents for calcium (Calcium Infinity ${ }^{\mathrm{TM}}$ Arsenazo III) and phosphate (the reduced phosphomolybdate method) obtained from the manufacturer. Measurement was performed on the fluid obtained from three disks incubated in the same conditions, and the mean \pm SD of the triplicate was considered.

\subsection{Scanning electron microscopy (SEM) and energy-dispersive X-ray analysis (EDX)}

Disks to be examined by SEM were processed as previously described [27]. SEM was performed on a JEOL 6301F (Paris, France) field emission microscope equipped with an energy-dispersive Xray microanalysis machine (EDX, Link ISIS, Oxford Instruments, Oxford, UK). EDX was done by point analysis at the surface of calcospherites to determine their composition. In each group, the size of 30 calcospherites was measured using Image freeware (NIH, Bethesda, MD) on SEM photographs.

\subsection{X-ray diffraction (XRD)}

Phase analysis of the synthesized HA or metal-doped HA was conducted primarily using XRD employing a PANalytical X'PERT MRD (PANalytical Ltd, Almelo, The Netherlands) using a $\mathrm{Cu} K$ radiation $(\lambda=1.5458 \AA$ ) and equipped with an X'Cellerator detector, which allows ultrafast data collection with no compromise with the diffractogram resolution. The diffractometer was operated at $40 \mathrm{kV}$ and $45 \mathrm{~mA}$ at a $2 \theta$ range of $10^{\circ}-37^{\circ}$ with a step size of $0.0125^{\circ}$ and an integration time of $75 \mathrm{~s}$ per step. Crystallographic identification of the metal-substituted HA was accomplished by comparing the experimental XRD patterns to standards complied by the Joint Committee on Powder Diffraction and Standards (ICDD PDF-2 Release 2004). The size of individual HA crystallites were calculated from XRD data using the Scherrer equation as previously reported [28]. Briefly, the peak of $25^{\circ}-27^{\circ} 2 \theta(002)$ was fit to define its full width at half maximum intensity $\left(B_{1 / 2}\right)$ :

$t=\frac{k \lambda}{B_{\frac{1}{2}} \cos \theta}$

where $t$ is the crystal size, as calculated for the (002) reflection, $\lambda$ is the wavelength of the $\mathrm{Cu} K_{\alpha}$ radiation and $k$ is the broadening constant varying with crystal habit and chosen as 0.9 for the elongated apatite crystallites, as previously reported [28].

The crystallinity noted by $X_{c}$ corresponds to the fraction of crystalline apatite phase in the investigated volume of powdered sample. An empirical relation between $X_{c}$ and the $B_{1 / 2}$ was deduced according to the equation as below:

$K_{A}=B_{\frac{1}{2}} \times \sqrt[3]{X_{c}}$

where $X_{c}$ is the crystallinity degree, $B_{1 / 2}$ is the full width of the peak at half intensity of the (002) reflection in $2 \theta$, and $K_{A}$ is a constant set at 0.24 , as previously established [28].

Interplanar distances ( $d$ values) obtained by X-ray diffraction (peak $25^{\circ}-27^{\circ} 2 \theta=$ planes 002 , peak $33-34^{\circ} 2 \theta=$ planes 300 ) allowed the calculation of parameters $a$ and $c$ from the crystal lattice. In a hexagonal system such as hydroxyapatite [21],

$a=\frac{6}{\sqrt{3 \times d_{(300)}}}$

$c=2 \times d_{(002}$

The error of the measurements being greater on plane (300) than on plane (002), the results obtained with parameter $c$ are given more weight. 


\subsection{Statistical analysis}

Data were expressed as means \pm SD. The significance of differences between groups was calculated by the analysis of variance procedure and, when a significant difference was found, Fisher's least significant post hoc difference test between group comparisons was used at the $95 \%$ significance level.

\section{Results}

\subsection{Chemical analysis}

The disks did not vary in shape or weight under standardized polymerization conditions. They were translucent and their mean weight was $157.5 \pm 3.5 \mathrm{mg}$, with no significant differences between groups. When incubated in SBF enriched with metal ions, there were significant differences between the metal groups and controls for chemical analysis. There was a lower amount of $\mathrm{Ca}$ and $\mathrm{P}$ and $\mathrm{a}$ lower $\mathrm{Ca} / \mathrm{P}$ ratio in the metal groups than in controls (Table 1 ). Indeed, there was a dramatic decrease in $\mathrm{P}$ and $\mathrm{Ca}$ with $1.06-\left(\mathrm{Ni}^{2+}\right.$ group) to 1.28 -fold $\left(\mathrm{Cr}^{3+}\right.$ group) and $1.15-\left(\mathrm{Ni}^{2+}\right.$ group) to 1.36 -fold $\left(\mathrm{Co}^{2+}\right.$ group), respectively, in the metal group vs. controls. As such, the $\mathrm{Ca} / \mathrm{P}$ ratio was affected by the presence of metal ions and a dramatic decrease of this parameter was observed of $1.05-\left(\mathrm{Cr}^{3+}\right.$ group) to 1.12 -fold ( $\mathrm{Co}^{2+}$ group) in metal groups compared to controls.

\subsection{SEM and characterization of hydroxyapatite calcospherites}

After incubation in the SBF, a white mineral layer composed of mineralized nodules was clearly seen at the surface of the pHEMACM disks by SEM. Mineralized nodules had a round shape (calcospherites); they were made of elementary tablets or plates of HA, packed together as reported previously [29]. A significant difference was found in calcospherite diameter between controls and metal groups (Fig. 1). In the control group, the calcospherite diameter was $1.78 \pm 0.1 \mu \mathrm{m}$. However, in the metal groups, the mean diameter was significantly higher, with 1.44-, 1.41- and 2.40-fold increases in the $\mathrm{Co}^{2+}, \mathrm{Cr}^{3+}$ and $\mathrm{Ni}^{2+}$ groups respectively. $\mathrm{Ca}$ and $\mathrm{P}$ could be localized on the EDX cartography; $\mathrm{Co}, \mathrm{Cr}$ and Ni were only localized in their respective groups (Fig. 2).

\subsection{Crystal size, crystallinity and lattice parameters reflected from the XRD pattern}

For quantitative purposes, the line broadening of the (002) reflection was used to evaluate the mean crystallite size. This method has previously been used by Li et al. [28] to assess the crystal size and crystallinity of strontium-substituted HA. The average crystal size and corresponding crystallinity of metal-HA were calculated from the XRD pattern, as shown in Fig. 3. The calculated crystal size of HA in our experimental approach was of $9.58 \pm 0.77 \mathrm{~nm}$. Interestingly, the calculated crystal size for

Table 1

Concentration of $\mathrm{Ca}^{2+}, \mathrm{PO}_{4}{ }^{3-}$ and metal/Ca ratio in pHEMA-CM disks incubated with $\mathrm{SBF}$ or metal-enriched $\mathrm{SBF}$ (mean $\pm \mathrm{SD})$.

\begin{tabular}{llllc}
\hline & $\begin{array}{l}\mathrm{Ca}^{2+}(\mathrm{mmol} \mathrm{l} \\
\text { per mg of } \\
\text { pHEMA })\end{array}$ & $\begin{array}{l}\mathrm{PO}_{4}{ }^{3-}\left(\mathrm{mmol} \mathrm{l}^{-1}\right. \\
\text { per mg of } \\
\text { pHEMA })\end{array}$ & $\begin{array}{l}\mathrm{Ratio}^{2+} \mathrm{Ca}_{4}{ }^{3-} \\
\mathrm{PO}^{2+}\end{array}$ & $\begin{array}{l}\text { Ratio Metal/ } \\
\mathrm{Ca}^{2+}\end{array}$ \\
\hline Control & $0.568 \pm 0.09$ & $0.305 \pm 0.07$ & $1.86 \pm 0.02$ & - \\
$\mathrm{Co}$ & $0.418 \pm 0.03^{*}$ & $0.252 \pm 0.02^{*}$ & $1.66 \pm 0.01^{*}$ & $0.19 \pm 0.03$ \\
$\mathrm{Cr}$ & $0.422 \pm 0.01^{*}$ & $0.238 \pm 0.05^{*}$ & $1.77 \pm 0.02^{*}$ & $0.054 \pm 0.005$ \\
$\mathrm{Ni}$ & $0.496 \pm 0.04^{*}$ & $0.288 \pm 0.03^{*}$ & $1.72 \pm 0.03^{*}$ & $0.157 \pm 0.04$ \\
\hline${ }^{*} p<0.05$ vs. control. & & & \\
\end{tabular}

$p<0.05$ vs. control
(A)

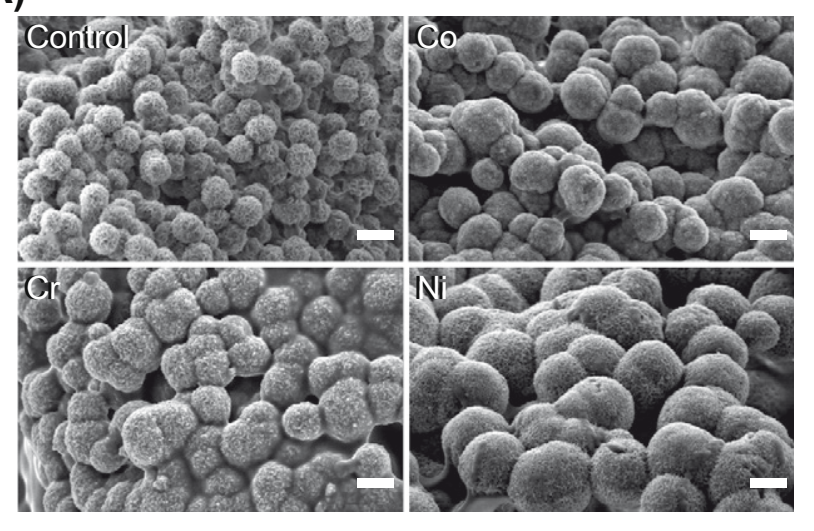

(B)

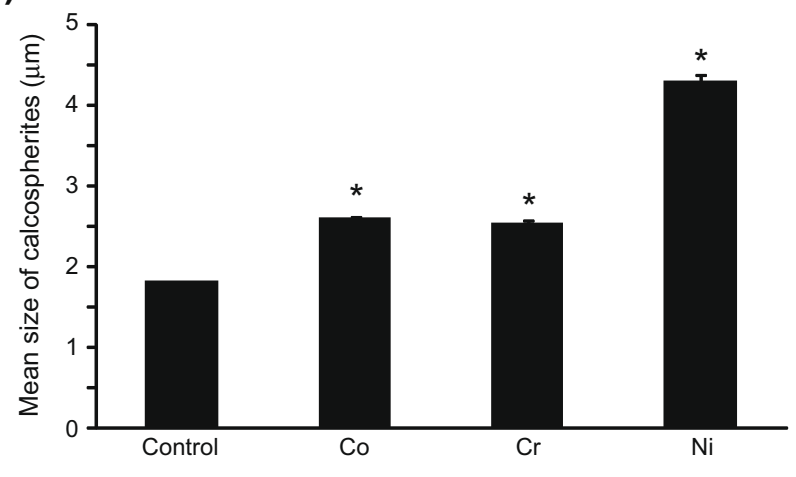

Fig. 1. Calcospherites developed at the surface of pHEMA-CM. (A) SEM micrographs; (B) mean size of calcospherites. Note that the mean size of calcospherites is significantly increased in metal-HA. $p<0.05$ vs. control HA. The white bar represents $2 \mu \mathrm{m}$.

Co-substituted HA, Cr-substituted HA and Ni-substituted HA was significantly increased by 1.27 -, 1.85 - and 1.37 -fold, respectively (Fig. 3B). The change of crystallinity on metal-substituted HA was similar to that of crystal size. The presence of $\mathrm{Co}^{2+}, \mathrm{Cr}^{3+}$ or $\mathrm{Ni}^{2+}$ in the SBF induced a significant increase in the crystallinity with the highest value observed in the $\mathrm{Cr}^{3+}$ group (Table 2).

The cell parameters of the samples are shown in Table 3. The error on the measurement being higher on plane (300) than on plane (002), the results obtained with parameter $c$ were favoured. The lattice parameter $c$ decreased slightly when $\mathrm{Ca}$ ions were replaced by metals ions in the HA framework.

\section{Discussion}

Metals are trace elements indispensable for life. However, their increased concentration can affect the mineral and enzyme status of the body (and consequently poses a threat to human health). The concentration of metals is significantly raised in patients with metal implants. Although it appears clear that metal ions, especially cobalt, chromium and nickel, have a direct effect on bone cells in vitro [13,30,31], little is known about the relationship between metal ions and hydroxyapatite mineral, the most abundant constituent of bone mineral. Recent reports suggest that bone strength depends on both bone quantity and bone quality, a term encompassing structural and material properties. Calcospherite growth on pHEMA-CM is a non-cellular model mimicking the mineralization of woven bone. Woven bone is a peculiar bone texture observed in the growing skeleton, fracture callus, bone remodelling around implant and metaplasia [32-34]. This system has been 
(A)

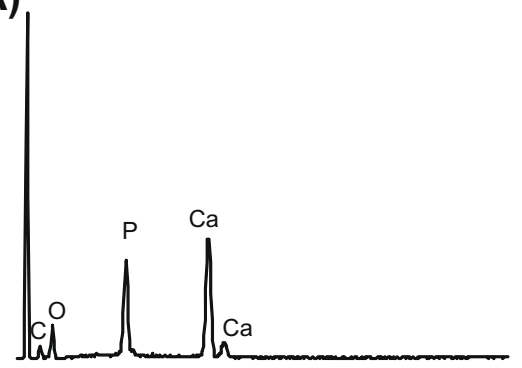

(B)

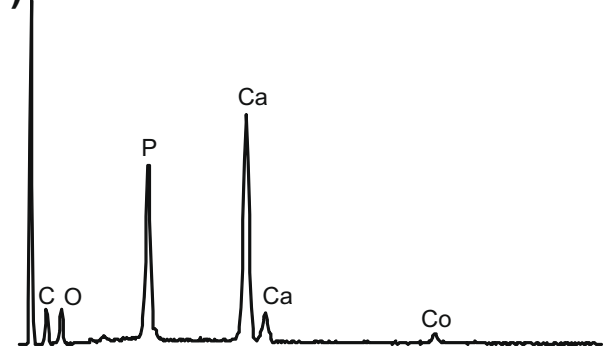

(C)

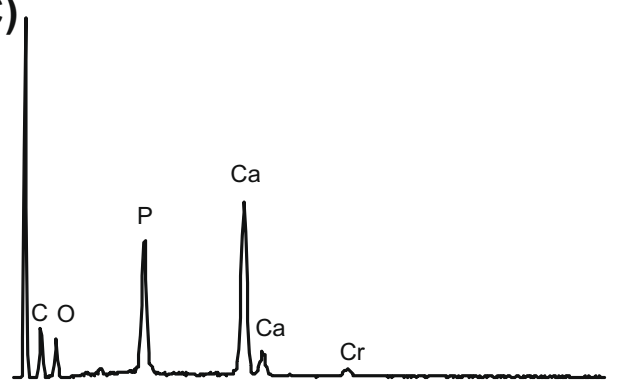

(D)

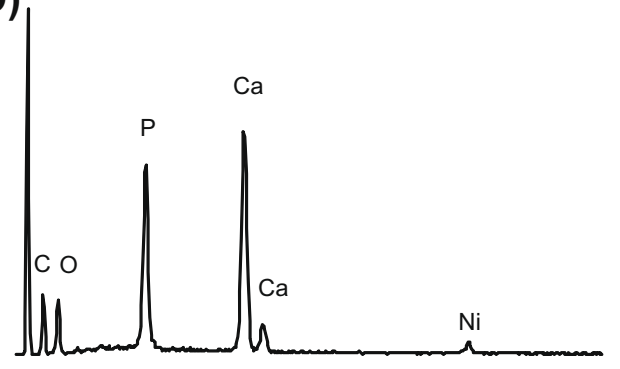

Fig. 2. EDX analysis of a control calcospherite (A) showing Ca and P colocalization. (B-D) represent EDX analysis of Co-dopped HA, Cr-dopped HA and Ni-dopped HA, respectively.

(A)

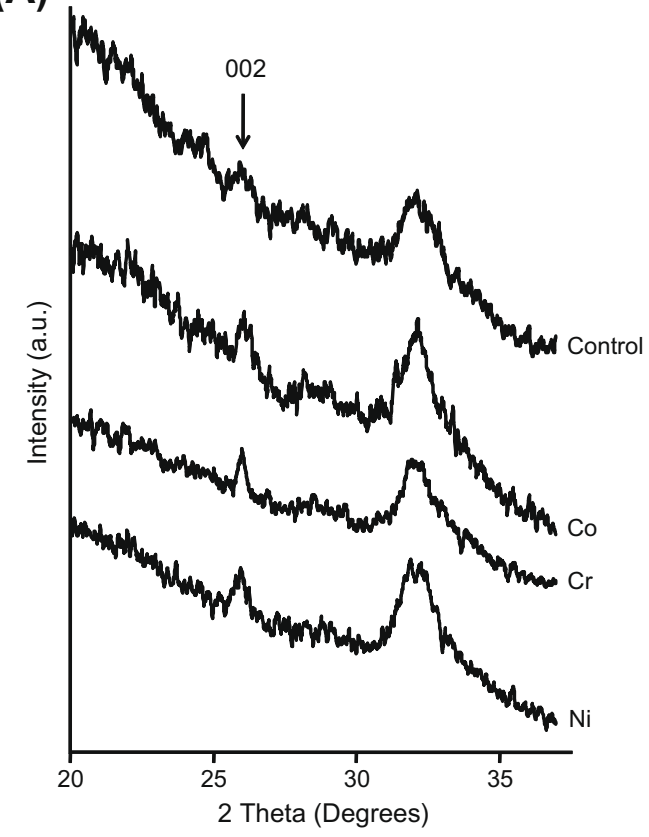

(B)

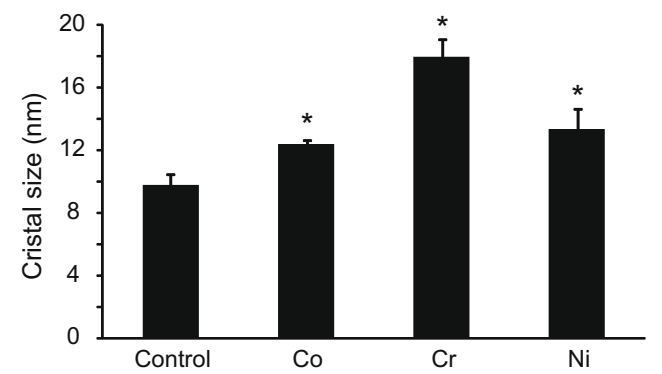

Fig. 3. XRD analysis of HA and metal-HA. (A) XRD patterns of HA and metal-HA; (B) mean size of the crystal. ${ }^{*} p<0.05$ vs. control HA. The arrow indicates the 002 reflection peak.

Table 2

Crystallinity of control HA and metal-HA (mean \pm SD).

\begin{tabular}{ll}
\hline & Crystallinity \\
\hline Control & $0.023 \pm 0.005$ \\
$\mathrm{Co}$ & $0.046 \pm 0.004^{*}$ \\
$\mathrm{Cr}$ & $0.143 \pm 0.030^{*}$ \\
$\mathrm{Ni}$ & $0.058 \pm 0.019^{*}$ \\
\hline
\end{tabular}

$p<0.05$ vs. control.
Table 3

Lattice parameters $a$ and $c$ of control HA and metal-HA (mean \pm SD).

\begin{tabular}{lll}
\hline & Lattice parameter $a(\AA)$ & Lattice parameter $c(\AA)$ \\
\hline Control & $9.703 \pm 0.024$ & $7.232 \pm 0.002$ \\
$\mathrm{Co}$ & $9.635 \pm 0.020$ & $6.286 \pm 0.004^{*}$ \\
$\mathrm{Cr}$ & $9.560 \pm 0.008^{*}$ & $6.849 \pm 0.003^{*}$ \\
$\mathrm{Ni}$ & $9.704 \pm 0.019$ & $6.864 \pm 0.012^{*}$ \\
\hline
\end{tabular}

$p<0.05$ vs. control. 
developed to successfully test the efficacy of bisphosphonate [35], cell adherence [36] and protein interaction [25] during bone crystal growth. It has also been used to assess the effect of iron incorporation into hydroxyapatite crystals [19]. In this study, we used this model to evaluate the direct role of cobalt, chromium and nickel on bone mineralization. We found that, in the presence of metals, the amount of phosphorous was significantly lower, indicating that metals inhibited the mineralization process. This effect was independent of cellular or enzyme interactions because of the model used in this study.

We also observed a decrease in the ratio $\mathrm{Ca} / \mathrm{P}$ in the metaldoped HA. This was expected as calcium is progressively substituted by metal ions during the mineralization process and, as such, the $\mathrm{Ca} / \mathrm{P}$ ratio is decreased. Furthermore, in metal-HA, the $\mathrm{Ca} / \mathrm{P}$ ratio is closer to the $\mathrm{Ca} / \mathrm{P}$ ratio usually observed for natural hydroxyapatite than in our control. On the other hand, metal ions significantly increased the calcospherite size, indicating plausible effects on the crystal parameters. Indeed, the XRD results indicated that incorporation of metal ions into the hydroxyapatite crystals narrowed the XRD peak of the (002) reflection, suggesting that the incorporation of metals into the mineral crystal increased the symmetry and thus improved the crystallinity. The ionic radii of $\mathrm{Co}(0.65 \AA), \mathrm{Cr}(0.69 \AA)$ and $\mathrm{Ni}(0.72 \AA)$ are smaller than the radius of Ca $(0.99 \AA)[39,40]$, which is in agreement with the observed decrease in lattice parameters for metal-HA. The change in the lattice parameters of metal-HA clearly demonstrated that metal ions were structurally incorporated, in other words, they did not just cover the surface of the crystals. The use of hydroxyapatite has been proposed in order to remove heavy metals and dangerous ions from solutions [40]. There is in fact isomorphic substitution of calcium with heavy divalent ions, which is correlated to their ionic radius and electronegativity [41]. As such, it has been reported that larger multivalent ions are more effectively removed in comparison to smaller ones [42]. In our study, cobalt had the highest metal $/ \mathrm{Ca}^{2+}$ ratio, followed by nickel and finally chromium. However, these ratios were determined by EDX; as EDX is only a semi-quantitative technique, they should therefore be taken carefully.

It has been suggested by others that the bone crystal size distribution plays an important role in bone fracture. Ovariectomized mice and osteopontin- and osteonectin-null mice exhibit larger bone crystals and increased brittleness [43]. Furthermore, Boskey [44] recently reviewed the effects of bone mineral crystal size and fragility, and concluded that bones with a preponderance of larger crystals have reduced resistance to load. In our study, we found that the crystal size was significantly increased in metalHA. This poses the question of the resistance of metal-HA to mechanical loading, which could potentially have other clinical implications. For instance, metal-on-metal hip resurfacing has been introduced on the market as an alternative to total joint replacement for treating young and active patients suffering from hip osteoarthritis [12]. However, in these patients the levels of circulating $\mathrm{Co}$ and $\mathrm{Cr}$ ions is dramatically increased [6], and one of the major concerns with this type of surgical approach is the apparition of unexplained femoral neck fracture $[8,45]$. To our knowledge, the quality of the bone mineral and the size of the crystals in these patients have not been investigated to date; however, it is plausible that metal ions incorporated in the mineral, in the vicinity of the implant, may increase the crystal size and hence could participate in elevating the rate of fracture.

\section{Conclusion}

We have shown that metal ions ( $\mathrm{Cr}$, Co and $\mathrm{Ni}$ ) can be incorporated into the hydroxyapatite crystal during mineralization and affect the crystal lattice parameters as well as the size of the crystal. The information obtained from this work would suggest that the quality of the mineral around metallic implants could be altered. However, further investigation should be conducted to further elucidate the effects of metal incorporation on bone mineral and the functional consequences.

\section{Acknowledgements}

This work was supported by grants from the Furlong Charitable Research Foundation, Contrat Region Pays de la Loire BIOREGOS2 and INSERM.

\section{References}

[1] Chen LC, Lippmann M. Effects of metals within ambient air particulate matter (PM) on human health. Inhal Toxicol 2009;21:1-31.

[2] Collery P, Maymard Y, Theophanides T, Khassanova L, Collery T. Metal ions in biology. John Libbey: New Barnet; 2008.

[3] Savarino L, Granchi D, Ciapetti G, Cenni E, Nardi Pantoli A, Rotini R, et al. Ion release in patients with metal-on-metal hip bearings in total joint replacement: a comparison with metal-on-polyethylene bearings. J Biomed Mater Res 2002;63:467-74.

[4] Brodner W, Bitzan P, Meisinger V, Kaider A, Gottsauner-Wolf F, Kotz R. Elevated serum cobalt with metal-on-metal articulating surfaces. J Bone Joint Surg Br 1997;79:316-21.

[5] Jacobs JJ, Skipor AK, Doorn PF, Campbell P, Schmalzried TP, Black J, Amstutz HC. Cobalt and chromium concentrations in patients with metal on metal total hip replacements. Clin Orthop Relat Res 1996;329:S256-63.

[6] De Smet K, De Haan R, Calistri A, Campbell PA, Ebramzadeh E, Pattyn C, et al. Metal ion measurement as a diagnostic tool to identify problems with metalon-metal hip resurfacing. J Bone Joint Surg Am 2008;90(Suppl. 4):202-8.

[7] Stulberg SD, Dorr LD, Freeman MA, Hungerford DS, Scott RD, Whiteside LA. Knee challenges: what would you do? Orthopedics 1994;17:869-74.

[8] Little CP, Ruiz AL, Harding IJ, McLardy-Smith P, Gundle R, Murray DW, et al. Osteonecrosis in retrieved femoral heads after failed resurfacing arthroplasty of the hip. J Bone Joint Surg Br 2005;87:320-3.

[9] Damborg F, Nissen N, Jorgensen HR, Abrahamsen B, Brixen K. Changes in bone mineral density (BMD) around the cemented Exeter stem: a prospective study in 18 women with 5 years follow-up. Acta Orthop 2008;79:494-8.

[10] Li MG, Rohrl SM, Wood DJ, Nivbrant B. Periprosthetic changes in bone mineral density in 5 stem designs 5 years after cemented total hip arthroplasty. No relation to stem migration. J Arthroplasty 2007;22:689-91.

[11] Lian YY, Pei FX, Yoo MC, Cheng JQ, Fatou CY. Changes of the bone mineral density in proximal femur following total hip resurfacing arthroplasty in osteonecrosis of femoral head. J Orthop Res 2008;26:453-9.

[12] Mabilleau G, Kwon YM, Pandit H, Murray DW, Sabokbar A. Metal-on-metal hip resurfacing arthroplasty: a review of periprosthetic biological reactions. Acta Orthop 2008;79:734-47

[13] Fleury C, Petit A, Mwale F, Antoniou J, Zukor DJ, Tabrizian M, et al. Effect of cobalt and chromium ions on human MG-63 osteoblasts in vitro: morphology, cytotoxicity, and oxidative stress. Biomaterials 2006;27:3351-60.

[14] Dizdaroglu M, Jaruga P, Birincioglu M, Rodriguez H. Free radical-induced damage to DNA: mechanisms and measurement. Free Radic Biol Med 2002;32:1102-15.

[15] Marnett LJ. Lipid peroxidation-DNA damage by malondialdehyde. Mutat Res 1999;424:83-95.

[16] Moreau MF, Gallois Y, Baslé MF, Chappard D. Gamma irradiation of human bone allografts alters medullary lipids and releases toxic compounds for osteoblast-like cells. Biomaterials 2000;21:369-76.

[17] Nichols KG, Puleo DA. Effect of metal ions on the formation and function of osteoclastic cells in vitro. J Biomed Mater Res 1997;35:265-71.

[18] Rousselle AV, Heymann D, Demais V, Charrier C, Passuti N, Basle MF. Influence of metal ion solutions on rabbit osteoclast activities in vitro. Histol Histopathol 2002;17:1025-32.

[19] Guggenbuhl P, Filmon R, Mabilleau G, Baslé MF, Chappard D. Iron inhibits hydroxyapatite crystal growth in vitro. Metabolism 2008;57:903-10.

[20] Jarup L. Hazards of heavy metal contamination. Br Med Bull 2003;68:167-82.

[21] Farlay D, Boivin G, Panczer G, Lalande A, Meunier PJ. Long-term strontium ranelate administration in monkeys preserves characteristics of bone mineral crystals and degree of mineralization of bone. J Bone Miner Res 2005;20:1569-78.

[22] Rowatt E, Sorensen ES, Triffit J, Viess A, Williams RJ. An examination of the binding of aluminum to protein and mineral components of bone and teeth. J Inorg Biochem 1997;68:235-8.

[23] Zaffe D, Bertoldi C, Consolo U. Accumulation of aluminium in lamellar bone after implantation of titanium plates, Ti-6Al-4V screws, hydroxyapatite granules. Biomaterials 2004;25:3837-44.

[24] Filmon R, Grizon F, Baslé MF, Chappard D. Effects of negatively charged groups (carboxymethyl) on the calcification of poly(2-hydroxyethyl methacrylate). Biomaterials 2002;23:3053-9. 
[25] Libouban H, Filmon R, Cincu C, Baslé MF, Chappard D. Fetuin and osteocalcin interact with calcospherite formation during the calcification process of poly (2-hydroxyethylmethacrylate) in vitro. J Raman Spectrosc 2009;40:1234-9.

[26] Yamada S, Nakamura T, Kokubo T, Oka M, Yamamuro T. Osteoclastic resorption of apatite formed on apatite- and wollastonite-containing glassceramic by a simulated body fluid. J Biomed Mater Res 1994;28:1357-63.

[27] Filmon R, Chappard D, Baslé MF. Scanning and transmission electron microscopy of poly (2-hydroxyethyl methacrylate)-based biomaterials. J Histotechnol 1997;20:343-6.

[28] Li ZY, Lam WM, Yang C, Xu B, Ni GX, Abbah SA, Cheung KM, Luk KD, Lu WW. Chemical composition, crystal size and lattice structural changes after incorporation of strontium into biomimetic apatite. Biomaterials 2007;28:1452-60.

[29] Filmon R, Chappard D, Montheard JP, Baslé MF. A composite biomaterial: poly 2(hydroxyethyl) methacrylate/alkaline phosphatase (pHEMA/AlkP) initiates mineralization in vitro. Cells Mater 1996;6:11-20.

[30] Mabilleau G, Gill HS, Sabokbar A. Effects of metal ions on osteoclastogenesis. Calcif Tissue Int 2007;80:S92.

[31] Mabilleau G, Gill HS, Sabokbar A. Effects of nickel ions on osteoclastogenesis. Bone 2007:40:S278.

[32] Chappard D, Aguado $E$, Huré G, Grizon F, Baslé MF. The early remodeling phases around titanium implants: a histomorphometric assessment of bone quality in a 3- and 6-month study in sheep. Int J Oral Maxillofac Implants 1999;14:189-96.

[33] Mabilleau G, Aguado E, Stancu IC, Cincu C, Baslé MF, Chappard D. Effects of FGF-2 release from a hydrogel polymer on bone mass and microarchitecture. Biomaterials 2008;29:1593-600.
[34] Schmidt A, Blanchet O, Dib M, Baslé MF, Ifrah N, Chappard D. Bone changes in myelofibrosis with myeloid metaplasia: a histomorphometric and microcomputed tomographic study. Eur J Haematol 2007;78:500-9.

[35] Filmon R, Baslé MF, Barbier A, Chappard D. Poly(2-hydroxy ethy methacrylate)-alkaline phosphatase: a composite biomaterial allowing in vitro studies of bisphosphonates on the mineralization process. J Biomater Sci Polym Ed 2000;11:849-68.

[36] Filmon R, Baslé MF, Atmani H, Chappard D. Adherence of osteoblast-like cells on calcospherites developed on a biomaterial combining poly(2-hydroxyethyl) methacrylate and alkaline phosphatase. Bone 2002;30:152-8.

[39] Chantawong V, Harvey NW, Bashkin VN. Comparison of heavy metal adsorptions by thai kaolin and ballclay. Water Air Soil Poll 2003;148:111-25.

[40] Saxena S, D'Souza SF. Heavy metal pollution abatement using rock phosphate mineral. Environ Int 2006;32:199-202.

[41] Perrone J, Fourest B, Giffaut E. Sorption of nickel on carbonate fluoroapatites. J Colloid Interface Sci 2001;239:303-13.

[42] Christopher JG, Tran Tri D, Suffet Meu HI. Electrosorption of inorganic salt from aqueous solutions using carbon aero gels. Environ Sci Technol 2002;36:3010-9.

[43] Paschalis EP, Boskey AL. Size Matters. Phoenix, AZ: American Society for Bone and Mineral Research; 2001.

[44] Boskey AL. Bone mineral crystal size. Osteoporos Int 2003;14:S16-21.

[45] Shimmin AJ, Back D. Femoral neck fractures following Birmingham hip resurfacing: a national review of 50 cases. J Bone Joint Surg $\mathrm{Br}$ 2005;87:463-4. 